\title{
Plasma Membrane Transporters as Biomarkers and Molecular Targets in Cholangiocarcinoma
}

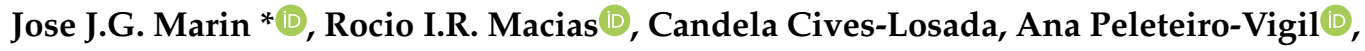 \\ Elisa Herraez ${ }^{+}(\mathbb{D})$ and Elisa Lozano ${ }^{+}$
}

HEVEFARM Group, Center for the Study of Liver and Gastrointestinal Diseases (CIBERehd), Carlos III National Institute of Health. University of Salamanca, IBSAL, 37007-Salamanca, Spain; rociorm@usal.es (R.I.R.M.); candelacives@usal.es (C.C.-L.); anapeleteiro@usal.es (A.P.-V.); elisah@usal.es (E.H.); elisa_biologia@usal.es (E.L.)

* Correspondence: jjgmarin@usal.es; Tel.: +34-663182872

+ These authors contributed equally to the coordination of this review article.

Academic Editors: Pietro Invernizzi and Chiara Raggi

Received: 25 January 2020; Accepted: 19 February 2020; Published: 21 February 2020

\begin{abstract}
The dismal prognosis of patients with advanced cholangiocarcinoma (CCA) is due, in part, to the extreme resistance of this type of liver cancer to available chemotherapeutic agents. Among the complex mechanisms accounting for CCA chemoresistance are those involving the impairment of drug uptake, which mainly occurs through transporters of the superfamily of solute carrier (SLC) proteins, and the active export of drugs from cancer cells, mainly through members of families B, C and $\mathrm{G}$ of ATP-binding cassette $(\mathrm{ABC})$ proteins. Both mechanisms result in decreased amounts of active drugs able to reach their intracellular targets. Therefore, the "cancer transportome", defined as the set of transporters expressed at a given moment in the tumor, is an essential element for defining the multidrug resistance (MDR) phenotype of cancer cells. For this reason, during the last two decades, plasma membrane transporters have been envisaged as targets for the development of strategies aimed at sensitizing cancer cells to chemotherapy, either by increasing the uptake or reducing the export of antitumor agents by modulating the expression/function of SLC and ABC proteins, respectively. Moreover, since some elements of the transportome are differentially expressed in CCA, their usefulness as biomarkers with diagnostic and prognostic purposes in CCA patients has been evaluated.
\end{abstract}

Keywords: ABC proteins; biliary cancer; chemoresistance; chemosensitivity; chemotherapy; hepatocellular carcinoma; SLC proteins; transporter; uptake

\section{Introduction}

The two most frequent liver cancers, i.e., hepatocellular carcinoma (HCC), followed in the order of incidence by cholangiocarcinoma (CCA), are extremely resistant to pharmacological treatment [1]. The mechanism of action of drugs used to treat these patients involves the interaction with their molecular targets, which, in most cases, are located intracellularly and, hence, require their entrance across the plasma membrane. Since, in aqueous solution, most of these drugs are electrically charged and, therefore, are not able to freely diffuse across the lipid bilayer, they must enter cancer cells through plasma membrane transporters. These proteins belong to the solute carrier (SLC) superfamily of proteins, which, in humans, is formed by more than 400 members organized into 65 families. They share a structure characterized by a variable number of transmembrane domains connected by intracellular and extracellular loops. On the other hand, several efflux pumps are involved in lowering the intracellular concentration of active agents by favoring the exit of the drugs. Most of these proteins are primary transporters driven by the energy generated during ATP hydrolysis and belong to the superfamily of ATP-binding cassette $(\mathrm{ABC})$ proteins. The general structure of these integral membrane 
proteins is characterized by two halves, each one formed by a region composed of several hydrophobic transmembrane alpha-helices bound to a bulky intracellular nucleotide-binding domain (NBD), where the catalytic site is located, and whose structure is used for their classification. In humans, there are seven families of $A B C$ proteins (from $A$ to $G$ ), of which only families $A B C B, A B C C$ and $A B C G$ contain members playing recognized roles in cancer chemoresistance. As a matter of fact, one of the most common mechanisms accounting for chemotherapy resistance in cancer cells is the upregulation of these $\mathrm{ABC}$ pumps that actively export a large number of different antitumor drugs, contributing to the multidrug resistance (MDR) phenotype of many types of tumors, including CCA [1], reducing drug bioavailability [2]. Therefore, "cancer transportome", defined as the set of transporters expressed at a given moment in cancer cells, is an essential element in an overall complex picture that determines the unsatisfactory response of CCA to the available chemotherapy.

Since some transporters are differentially expressed in CCA and HCC, some attempts have been made to use them as biomarkers in diagnosis and prognosis and, even when they are expressed in both tumoral cholangiocytes and hepatocytes, they can be useful as targets to develop strategies aimed at sensitizing tumor cells to chemotherapy, either by increasing the uptake or reducing the export of anticancer drugs.

\section{Carriers as Biomarkers}

The usefulness of transport proteins as biomarkers for the diagnosis, prognosis, or monitoring the response to therapy for several types of cancer, including primary liver tumors, has been described in recent studies. Transport proteins that are expressed at the plasma membrane of cancer cells are identical or similar to those found in healthy cells under physiological conditions; although, in tumor cells, changes in their expression levels and the appearance of genetic and epigenetic variations are frequent and can contribute to chemotherapy resistance. Some transport proteins are ubiquitous, whereas others are tissue-specific or even are expressed only in one type of cells in a specific tissue. The latter ones are of particular interest as biomarkers, since they may permit to distinguish different types of tumors based on the organ or the cell type from where they are originated (Table 1).

Table 1. Plasma membrane transporters with potential usefulness as biomarkers.

\begin{tabular}{|c|c|c|c|c|c|}
\hline Usefulness & Gene & Protein & Levels in CCA & Levels in HCC & Potential Interest/Evidences \\
\hline \multirow[b]{2}{*}{ Diagnosis } & SLC10A2 & ASBT & Mild & N.D. & To distinguish CCA and HCC/in vitro/in vivo/IHC \\
\hline & SLC2A1 & GLUT1 & High & Low & To distinguish CCA and $\mathrm{HCC} / \mathrm{IHC}$ \\
\hline \multirow{4}{*}{$\begin{array}{l}\text { Response to } \\
\text { chemotherapy }\end{array}$} & $S L C 29 A 1$ & ENT1 & Variable & Variable & $\begin{array}{l}\text { Prediction of response to nucleoside analogues/Expression } \\
\text { associated with gemcitabine response in patients }\end{array}$ \\
\hline & $S L C 22 A 1$ & OCT1 & Low & Low & $\begin{array}{l}\text { Prediction of response to sorafenib/Expression and location } \\
\text { associated with sorafenib response in patients }\end{array}$ \\
\hline & $A Q P 5$ & AQP-5 & High & High & $\begin{array}{l}\text { Prognosis and drug sensitivity to gemcitabine/IHC/Expression } \\
\text { related with drug response }\end{array}$ \\
\hline & $A B C C 3$ & MRP3 & High & Low & Biomarker of drug resistance to sorafenib/in vitro evidences \\
\hline Prognosis & $S L C 2 A 2$ & GLUT2 & High & High & Marker of high-grade biliary tumors/IHC \\
\hline
\end{tabular}

Apical sodium-dependent bile acid transporter (ASBT); aquaporin 1/5 (AQP-1/5); cholangiocarcinoma cholangiocarcinoma (CCA); copper transporter 1 (CTR1); equilibrative nucleoside transporter 1 (ENT1); glucose transporter 1/2 (GLUT1/2); hepatocellular carcinoma (HCC); immunohistochemistry (IHC); multidrug resistance protein 1 (MDR1); multidrug resistance-associated protein 1/3 (MRP1/3); aquaporin 1/5 (AQP-1/5); not detected (N.D.). CCA and HCC levels are compared to adjacent non-tumor tissue.

Regarding the liver, transport proteins involved in the uptake and efflux of bile acids [3] meet these requirements and have been proposed as biomarkers [4]. This is the case of the apical sodium-dependent bile acid transporter (ASBT, gene symbol SLC10A2), located in the apical membrane of cholangiocytes, 
whose expression is maintained or slightly increased in CCA [5]. Since ASBT is not expressed in hepatocytes, the detection of this transporter can be useful to differentiate CCA from HCC.

On the other hand, several members of the family of organic anion-transporting polypeptides (OATPs) are expressed in healthy hepatocytes and cholangiocytes. Namely, OATP1B1 and OATP1B3 (gene symbols SLCO1B1 and SLCO1B3, respectively), which play an important role in the uptake of bile acids and many other endogenous and xenobiotic compounds by the hepatocytes, are expressed in HCC [6,7]. However, understanding the relevance of members of the OATP family as biomarkers in CCA requires further investigation.

The copper transporter 1 (CTR1, gene symbol SLC31A1) is able to transport platinum derivatives, and the reduction in CTR1 expression observed in CCA [7] might result in enhanced chemoresistance to these drugs. Also, a relationship between the existence of polymorphisms in the SLC31A1 gene and the response to gemcitabine-platinum treatment in biliary tract cancer patients has been reported [8].

Another interesting marker for the prediction of response to treatment based on nucleoside analogs is the presence in the tumor cell plasma membrane of the equilibrative nucleoside transporter 1 (ENT1, gene symbol SLC29A1), which has been associated with better outcome in patients receiving gemcitabine as an adjuvant in resected CCA and as first-line treatment in advanced biliary tract cancer $[9,10]$.

The organic cation transporter 1 (OCT1, gene symbol SLC22A1) is present both in healthy cholangiocytes and hepatocytes. The detection of OCT1 in the plasma membrane of cancer cells may be considered as a prognostic biomarker in sorafenib-based HCC therapy [11,12]. Low OCT1 expression in CCA has also been associated with the refractoriness of this tumor to sorafenib in animal models and in in vitro assays [13]. Moreover, the analysis of OCT1 expression in different types of liver lesions, together with that of other SLC22A family members, such as OCT3 (gene symbol SLC22A3), has been proposed as a diagnostic marker of intrahepatic lesions [14]. However, a recent study provides evidence for age-related changes in transcriptome liver profile for important drug-related genes, such as SLC22A1, whose expression was higher in the group of older people [15], thus requiring stratification for the use of these genes as biomarkers.

High levels of glucose transporter 1 (GLUT1, gene symbol SLC2A1) have been found in several cancers, including intrahepatic CCA (iCCA), associated with hypoxia, which is consistent with the elevation of anaerobic metabolism together with the poor cell differentiation and metastasis that are characteristic of these tumors [16]. GLUT1 has been proposed as a biomarker for the detection of bile duct carcinoma and for distinguishing between CCA from HCC [17]. In addition, the expression of GLUT2 (gene symbol SLC2A2) was proposed as a marker of high-grade biliary intraepithelial neoplasia lesions [16].

The expression levels of monocarboxylate transporter 4 (MCT4, gene symbol SLC16A3) increase with HCC progression, while that of MCT2 (gene symbol SLC16A7) is lost in advanced HCC and is associated with a better prognosis [18]. The value of this marker in CCA is not known.

The overexpression of the anion exchanger 2 (AE2, gene symbol SLC4A2) has been associated with HCC development [19], while inadequate AE2 expression in cholangiocytes may lead to the development of chronic cholangiopathies [20], which are risk factors of CCA.

Aquaporin-1 (AQP-1, gene symbol $A Q P 1$ ) has been proposed as a selective marker for differentiated cholangiocytes and as a useful biomarker to immunohistochemically differentiate between CCA and HCC and metastatic colorectal carcinomas [21], while high AQP-5 (gene symbol AQP5) expression was associated with better prognosis and drug sensitivity in biliary tract carcinoma [22].

Phosphohippolin (PPH, FXYD6 gene), a transmembrane protein that functions as an ion channel and affects the activity of $\mathrm{Na}^{+} / \mathrm{K}^{+}$-ATPase, has been found upregulated in CCA compared with normal bile duct tissue, and has been proposed as a new potential biomarker and therapeutic target for CCA [23] (Figure 1). 


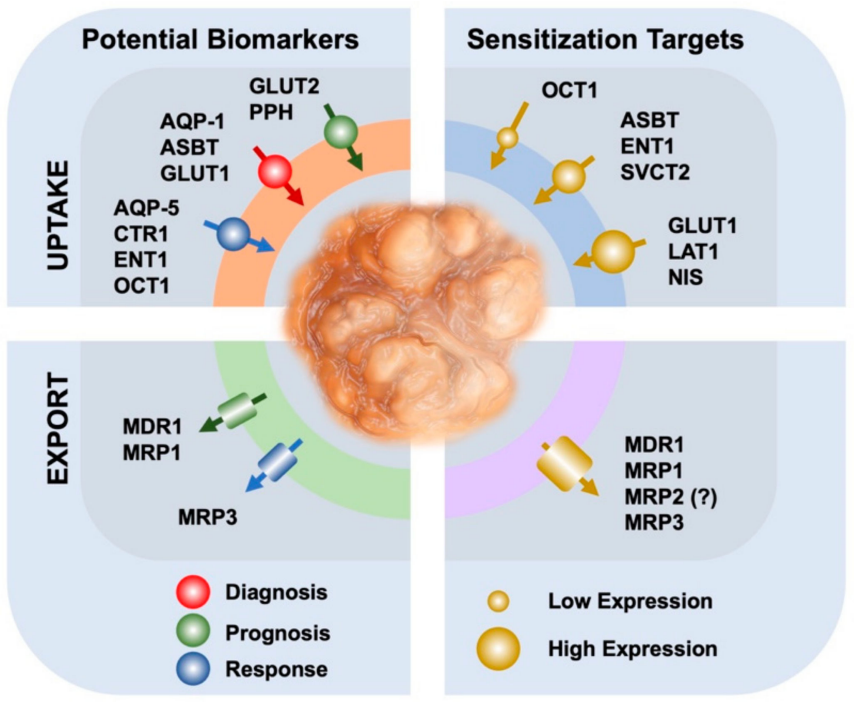

Figure 1. Schematic representation of the role in cholangiocarcinoma of uptake (up) and export (down) transporters as biomarkers for diagnosis and prediction of response to chemotherapy (left) or as targets for strategies of chemosensitization to antitumor drugs (right). Aquaporin-1/5 (AQP-1/5); apical sodium-dependent bile acid transporter (ASBT); cooper transporter (CTR1); equilibrative nucleoside transporter 1 (ENT1); glucose transporter 1/2 (GLUT1/2); L-type amino acid transporter-1 (LAT1); multidrug resistance protein 1 (MDR1); multidrug resistance-associated protein 1/3 (MRP1/3); sodium-iodide symporter (NIS); organic cation transporter 1 (OCT1); Phosphohippolin (PPH); sodium-dependent vitamin C transporter 2 (SVCT2).

Among members of the family $\mathrm{ABCB}$ of the $\mathrm{ABC}$ proteins, the high expression of P-glycoprotein or multidrug resistance protein 1 (MDR1, gene symbol $A B C B 1$ ) detected by immunohistochemistry in HCC was associated with a bad prognosis [24,25]; moreover, this pump has been proposed as a valuable biomarker of prognosis in gallbladder cancer [26]. In the same family, the bile salt export pump (BSEP, gene symbol $A B C B 11$ ), which is also located at the canalicular membrane of healthy hepatocytes, has been suggested to be a sensitive and specific marker of HCC [27], whereas the phospholipid translocase MDR3 (gene symbol $A B C B 4$ ), which is located in the apical membrane of hepatocytes and cholangiocytes, may be a useful marker to discriminate immunohistochemistry, HCC and iCCA from hepatoid carcinomas [28]. Mutations in both pumps (BSEP and MDR3) have been described in some cases of pediatric patients with CCA [29,30], which may lead to increased CCA susceptibility.

Contradictory information has been published regarding the expression in CCA of another $\mathrm{ABC}$ protein, the multidrug resistance-associated protein 2, (MRP2, gene symbol $A B C C 2$ ), which is located at the apical pole of the hepatocyte plasma membrane. On the one hand, MRP2 has been detected by immunohistochemistry, not only in HCC (72/80 cases), but also in CCA (52/54 cases) [31], whereas another study has reported the presence of MRP2 in only a low proportion of gallbladder tumors (4/14 cases), but an undetectable expression in all CCA assayed (0/7 cases) [2]. MRP3 (gene symbol $A B C C 3)$, located at the basolateral membrane of both hepatocytes and cholangiocytes, has been found moderately expressed in only some cases of HCC (15/80 cases) and highly expressed in CCA specimens (24/54 cases) [31]. These results do not support the use of these ABC proteins as markers for the differential diagnosis between HCC and CCA; however, the positivity of the staining could be useful for an association with other clinical parameters. In fact, the over-expression of MRP3 has been proposed as a marker of resistance to sorafenib in HCC-derived cell lines [32]. Whether this concept can be extrapolated to patients has not been confirmed. Regarding iCCA, the determination of mRNA levels by RT-qPCR revealed that only MRP1 (gene symbol $A B C C 1$ ) was a candidate prognostic biomarker; while the loss of breast cancer resistance protein (BCRP, gene symbol ABCG2) expression by immunohistochemistry, but not of MDR1 or MRP1, was associated with more aggressive tumor progression [33] (Figure 1). 


\section{The Usefulness of Transporters in Drug Targeting}

Owing to the fact that the uptake of most anticancer drugs is a crucial step for their efficacy and this mainly occurs through plasma membrane proteins, it has been hypothesized that some of these transporters could be used as targets for directing chemotherapy (Figure 1). As mentioned above, the expression levels of some of these transporters are maintained or even increased in CCA, which might facilitate the intracellular accumulation and hence the action of their substrate drugs (Table 2). Thus, gemcitabine can be taken up by nucleoside transporters, such as CNTs and ENTs (SLC28 and SLC29 families) [34], whose expression levels have been associated with gemcitabine response in CCA patients $[35,36]$.

Table 2. Plasma membrane transporters with potential usefulness as targets in CCA.

\begin{tabular}{|c|c|c|c|c|c|}
\hline Gene & Protein & Levels $^{a}$ & Substrates & Role & Modulation \\
\hline SLC102 & ASBT & Mild & Bile acid derivatives & Drug uptake & in vitro and in vivo evidences \\
\hline$S L C 22 A 1$ & OCT1 & Low & Sorafenib & Drug uptake & $\begin{array}{c}\text { Decitabine and cisplatin temporarily } \\
\text { induce its expression. In vitro and } \\
\text { in vivo evidences }\end{array}$ \\
\hline$S L C 29 A 1$ & ENT1 & Variable & Nucleoside analogs & Drug uptake & $\begin{array}{l}\text { Cisplatin temporarily induces its } \\
\text { expression. Associated to gemcitabine } \\
\text { response in patients }\end{array}$ \\
\hline$S L C 2 A 1$ & GLUT1 & High & Glucose & $\begin{array}{l}\text { Inhibition of GLUT1 } \\
\text { reduces tumor metabolic } \\
\text { activity }\end{array}$ & Quercetin inhibits GLUT1 in vitro \\
\hline$S L C 23 A 2$ & SVCT2 & Mild & $L$-Ascorbic acid & $\begin{array}{l}\text { Uptake of } L \text {-ascorbic } \\
\text { acid induces cytotoxicity }\end{array}$ & in vitro and in vivo evidences \\
\hline$A B C C 1$ & MRP1 & High & $\begin{array}{c}\text { Mitomycin C, } \\
\text { gemcitabine, } \\
\text { doxorubicine, sorafenib, } \\
\text { 5-FU }\end{array}$ & Drug efflux & $\begin{array}{l}\text { Expression modulated by tannic acid, } \\
\text { isomorellin and metformin in vitro }\end{array}$ \\
\hline$A B C C 2$ & MRP2 & Unclear & $\begin{array}{l}\text { Mitomycin C, } \\
\text { gemcitabine, 5-FU }\end{array}$ & Drug efflux & $\begin{array}{l}\text { In vitro evidences. Expression modulated } \\
\text { by tannic acid. }\end{array}$ \\
\hline$A B C C 3$ & MRP3 & High & Sorafenib & Drug efflux & In vitro evidences \\
\hline
\end{tabular}

${ }^{a}$ Expression levels in CCA as compared with adjacent non-tumor tissue. 5-fluorouracil (5-FU); tyrosine kinase inhibitors (TKIs); apical sodium-dependent bile acid transporter (ASBT); copper transporter 1 (CTR1), organic cation transporter 1 (OCT1); equilibrative nucleoside transporter 1 (ENT1); glucose transporter 1 (GLUT1); L-type amino acid transporter-1 (LAT1); sodium-dependent vitamin C transporter 2 (SVCT2); sodium-iodide symporter (NIS); multidrug resistance protein 1 (MDR1); multidrug resistance-associated protein 1/2/3 (MRP1/MRP2/MRP3); 5-fluorouracil (5-FU); tyrosine kinase inhibitors (TKIs).

Since bile acid transporters are expressed at the plasma membrane of cholangiocytes and this feature is preserved in CCA, the possibility to vectorize anticancer drugs conjugated with bile acids towards these tumors has been explored [5]. Several cytostatic bile acid derivatives named "Bamets" - from bile acid (BA) and metal (MET) — have been previously synthesized and evaluated in liver and intestinal cells. The results revealed an efficient uptake by bile acid transporters expressed in the cells of the enterohepatic circuit $[37,38]$. One of these compounds, named Bamet-UD2, obtained by conjugation of cisplatin and two ursodeoxycholate moieties, has proved to be useful in experimental models of CCA. Thus, Bamet-UD2 has potent in vitro cytostatic activity and in vivo antitumor effect, and markedly lower side effects than the parent drug cisplatin [5,39]. Interestingly, Bamet-UD2 uptake by CCA cells was mediated by ASBT, whose expression levels are relatively well preserved in CCA [5].

The L-type amino acid transporter-1 (LAT1, gene symbol SLC7A5), is a sodium-independent carrier expressed at the plasma membrane of many cells, where this is involved in the transport of neutral amino acids, including several essential ones. LAT1 is highly expressed in many types of cancer, including CCA, where it may play a role in carcinogenesis and progression [40]. Using in vitro assays, experimental downregulation of LAT1 has been demonstrated to suppress CCA cell invasion and 
migration, which suggests that LAT1 constitutes a potential therapeutic target for treating CCA [41]. Furthermore, JPH203 (also known as KYT0353), a selective inhibitor of this transporter, has been shown to induce apoptosis, cell cycle arrest and impaired tumor growth in both in vitro and in vivo models of CCA [42].

Through a completely different approach, although also involving plasma membrane transporters, several studies have aimed at inhibiting tumor growth by manipulating cancer cell metabolism, for instance, by impairing glucose uptake through GLUT1, whose expression in CCA is high, as mentioned above [17]. In vitro experiments performed with CCA cells (TFK-1) revealed that the antioxidant flavonoid quercetin inhibited GLUT1 along with the metabolic activity, which was accompanied by DNA damage and enhanced cell death by activation of apoptosis [43].

Surprisingly, L-ascorbic acid has been reported to induce cytotoxicity in CCA cells by generating intracellular reactive oxygen species (ROS), and subsequently DNA damage, ATP depletion, and inhibition of the "mammalian target of rapamycin" (mTOR) survival pathway, which results in a synergistic effect with cisplatin both in vitro and in vivo. These effects depend on the expression of the sodium-dependent vitamin C transporter 2 (SVCT2, gene symbol SLC23A2). Accordingly, the knockdown of SVCT2 made CCA cells resistant to the treatment with L-ascorbic acid. These results suggest that SVCT2 expression levels may serve as a positive outcome predictor for treatment with vitamin C in CCA patients [44].

Another transporter that has been detected at high levels in the plasma membrane of a significant proportion of human CCA is the sodium-iodide symporter (NIS, gene symbol SLC5A5). NIS plays an essential role in the uptake of ${ }^{131} \mathrm{I}$ and has been proposed as a potential target for radioiodine therapy in CCA [45].

\section{Overcoming Chemoresistance by Manipulation of Uptake Transporters}

The transporter of organic cation, OCT1, has been associated with the uptake of the tyrosine kinase inhibitor (TKI) sorafenib by cancer cells [46]; however, in CCA, a marked reduction in OCT1 function occurs due to a decrease in mRNA levels and the predominance of aberrant splicing variants $[7,46]$. This fact has also been observed in HCC [47], where this was associated with a reduced amount of OCT1 in the plasma membrane and unsatisfactory response to sorafenib [12]. In order to overcome this situation, a novel gene therapy approach has been developed to enhance the levels of this transporter and to improve sorafenib efficacy. The strategy consisted of adenoviral vectors bearing the OCT1 coding sequence under the transcriptional control of the oncogene BIRC5 promoter, which is selectively active in CCA cells. The evaluation of these vectors, in both in vitro and in vivo CCA models, revealed that the transduction with these adenoviral vectors resulted in an increased expression of OCT1, which selectively occurred in the plasma membrane of CCA cells, but not in the healthy liver tissue. As a consequence, the uptake of sorafenib by the tumor was enhanced and the response to treatment with this drug resulted in efficient tumor growth inhibition [13].

Similar to what happens with OCT1, other SLC transporters are also downregulated in CCA, which affects the efficacy of the drugs that are taken up through them. Moreover, chemotherapy can alter the expression of several transporters not necessarily involved in the uptake of the administered drug. Thus, cisplatin treatment can temporarily induce the expression of certain transporters such as CNT1 (gene symbol SLC28A1), CNT3 (gene symbol SLC28A3), ENT1 and OCT1. Taking advantage of these changes, it has been proposed to carry out sequential cycles of chemotherapy in which cisplatin would be alternated with drugs taken up by these transporters, such as gemcitabine and sorafenib, to improve the overall response [48].

\section{Strategies to Reduce Drug Efflux}

Concomitant inhibition of drug efflux pumps through the use of antitumoral drugs represents a promising strategy for overcoming CCA chemoresistance. In this sense, a high number of new molecules, called chemosensitizers, have been developed to inhibit or modulate ABC transporters, 
restore drug accumulation and, hence, their chemotherapeutic efficacy. This has led to the development of three generations of $\mathrm{ABC}$ inhibitors so far. Most of them are structure-based inhibitors of MDR1, which is considered a prototypic $\mathrm{ABC}$ drug pump able to export (out of tumor cells) a large variety of drugs, such as doxorubicin, etoposide, paclitaxel, vinblastine and sorafenib [49]. Moreover, MDR1 has been found overexpressed both in CCA cell lines and in clinical samples of biliary tumors [50]. The first generation of chemosensitizers included Food and Drug Administration-approved drugs non-specifically designed for this purpose, such as verapamil, cyclosporine A or quinine. They had a potent in vitro activity, but unacceptable side effects in healthy tissues in vivo [51]. The second generation of these inhibitors, which included, for instance, valspodar and PSC-833, were developed to specifically target drug efflux transporters. They showed less toxicity, but also had off-target effects and lacked significant efficacy in clinical trials [52,53]. Accordingly, a third generation of ABC modulators was developed to improve both potency and specificity. Although in preclinical studies with acute myeloid leukemia patients some of these drugs, such as tariquidar, elacridar, zosuquidar and laniquidar, showed a strong ability to inhibit MDR1 at very low concentrations, they have not demonstrated sufficient clinical efficacy to be considered further [54] and, unfortunately, none of these compounds have been incorporated into clinically accepted treatments. Therefore, efficient and non-toxic chemosensitizers are still being sought, mainly among natural compounds. Although still under investigation, some of them have shown promising characteristics. This group includes tannic acid, a plant-derived polyphenol, which has demonstrated its ability to inhibit CCA growth both in vitro and in vivo [55]. This compound also reduces the expression of several export pumps, such as MDR1, MRP1 and MRP2, involved in CCA chemoresistance [7,50], enhancing 5-fluorouracil (5-FU), mitomycin $\mathrm{C}$ and gemcitabine cytotoxicity in CCA cells [56].

More recently, other natural compounds have been suggested as promising agents for CCA treatment in combination with antitumor drugs. Among them, $\beta$-escin, the most active compound of the horse chestnut seed (Aesculus hippocastanum), is a potent reverser of MDR1-mediated resistance, able to sensitize CCA cells to common anticancer drugs [57]. Moreover, isomorellin or forbesione, obtained from Garcinia hanburyi, have shown significant synergistic effects with doxorubicin in CCA cells in vitro by downregulating MRP1 [58].

In addition to natural products, there are numerous synthetic compounds that have exhibited chemosensitizing properties in CCA when combined with anticancer drugs, through modulation of ABC transporters. These include some drugs, such as metformin, which sensitizes CCA cells to both sorafenib and 5-FU by reducing MRP1 expression through modulation of the AMPK/mTOR pathway [59] and simvastatin, that decreases CCA cell viability and ABCA1 and ABCG1 expression by acting through a pathway independent on the serine-threonine protein kinase AKT [60]. Tamoxifen may also reverse the MDR phenotype of CCA cells by enhancing the chemotherapeutic effects due to its competitive inhibition of MDR1 [61]. Additionally, several TKIs have shown potential as chemosensitizers, mainly by inhibiting MDR1, MRPs and BCRP [62-65]. Many of these drugs are themselves substrates of these $\mathrm{ABC}$ pumps or directly inhibit their function by blocking the ATP-binding site and thus promoting drug accumulation.

The inhibition of the nuclear factor kappa B (NF-kB) by the synthetic compound dehydroxymethylepoxyquinomicin (DHMEQ) also enhances the sensitivity of CCA cells to several antitumor drugs, such as 5-FU, cisplatin and doxorubicin, presumably due to its ability to induce MDR1 and BCRP downregulation [66].

In the last years, alternative strategies for overcoming multidrug resistance by regulating $A B C$ transporter expression have been proposed. These include approaches based on the use of antisense oligonucleotides, ribozymes, RNA interference and CRISPR/Cas9 technology. However, the literature regarding the use of gene therapy to chemosensitize CCA is scarce. Overexpression of ten-eleven translocation 1 (TET1), a methylcytosine dioxygenase that catalyzes DNA demethylation, enhances the sensitivity of CCA to gemcitabine, accompanied by a decrease in MDR1 expression [67]. In addition, overexpression of miR-199a-3p in the presence of cisplatin could decrease the proliferation rate and 
increase apoptosis of CCA cells, probably by regulating the expression of its target gene mTOR and reducing that of MRP1 [68]. Furthermore, inhibition of $W n t / \beta$-catenin pathway by $\beta$-catenin siRNA also reverses the MDR phenotype of CCA chemoresistant cells by downregulating MDR1 [69].

\section{Conclusions and Perspectives}

Since cellular uptake is an essential step in the mechanisms of action of many anticancer drugs, whose activity depends on the intracellular levels of active agents, an important role of SLC and ABC proteins in determining CCA chemoresistance has been demonstrated.

It should be considered that the transportome involved in the MDR phenotype of CCA is not a steady-state feature of cancer cells but a dynamic trait that responds to pharmacological treatment in a Darwinian way of evolution among cancer cell populations, in which key features selecting more chemoresistant clones may be present before the treatment, appear during treatment or be potentiated by the treatment. This has serious consequences regarding the relapse and, hence, the clinical outcome and constitutes an important difficulty in the use of changes in expression levels or the presence of genetic variants of transporters as biomarkers.

Regarding the use of transporters as pharmacological targets, an important feature is the location of these proteins in the plasma membrane, because this is an essential requirement for their functionality. Thus, in addition to measure mRNA and protein levels, it would be necessary to confirm the correct subcellular location, e.g. using immunofluorescent staining. Moreover, it should be kept in mind that some transporters, even correctly targeted to the plasma membrane, present single nucleotide polymorphisms (SNPs) that inactivate their carrier function, as described for OCT1 [46].

Based on the advances in the field, it is evident that, in order to improve the response rates of the pharmacological treatment of CCA, in addition to more effective novel drugs, combined chemosensitizing strategies are required. With this aim, three lines of action need to be fostered: (i) to increase the expression of functional uptake transporters using gene therapy strategies, (ii) to chemically synthesize novel molecules with more selective and potent ability to inhibit export pumps or to vectorize active agents through uptake transporters and iii) to improve the selective delivery of chemotherapy to tumor cells using tools provided by advances in nanomedicine. On the other hand, the rapid increase in our knowledge regarding the biology of extracellular vesicles released by cancer cells, and the technology required for their isolation and characterization, make these nanoparticles excellent tools to indirectly explore the presence of SLC and ABC proteins in tumor cells and, hence, use them as biomarkers with diagnostic and prognostic purposes in CCA patients.

Author Contributions: All authors have contributed substantially to the elaboration of this manuscript, which has been read and approved by all of them. All authors have read and agreed to the published version of the manuscript.

Funding: This study was funded by the CIBERehd (EHD15PI05/2016) and "Fondo de Investigaciones Sanitarias, Instituto de Salud Carlos III", Spain (PI16/00598, co-funded by European Regional Development Fund/European Social Fund, "Investing in your future"); Spanish Ministry of Economy, Industry and Competitiveness (SAF2016-75197-R); “Junta de Castilla y Leon" (SA063P17); AECC Scientific Foundation (2017/2020), Spain; and "Centro Internacional sobre el Envejecimiento" (OLD-HEPAMARKER, 0348_CIE_6_E), Spain; Fundación University of Salamanca, Spain (PC-TCUE18-20_051). CCL and APV were supported by pre-doctoral scholarships (FPU) funded by the Ministry of Science, Innovation and Universities, Spain. EL was supported by a postdoctoral contract by the University of Salamanca, Spain.

Conflicts of Interest: The authors declare no conflict of interest.

\section{References}

1. Marin, J.J.G.; Lozano, E.; Briz, O.; Al-Abdulla, R.; Serrano, M.A.; Macias, R.I.R. Molecular Bases of Chemoresistance in Cholangiocarcinoma. Curr. Drug Targets 2017, 18, 889-900. [CrossRef]

2. Rau, S.; Autschbach, F.; Riedel, H.D.; Konig, J.; Kulaksiz, H.; Stiehl, A.; Riemann, J.F.; Rost, D. Expression of the multidrug resistance proteins MRP2 and MRP3 in human cholangiocellular carcinomas. Eur. J. Clin. Investig. 2008, 38, 134-142. [CrossRef] [PubMed] 
3. Marin, J.J.; Macias, R.I.; Briz, O.; Banales, J.M.; Monte, M.J. Bile Acids in Physiology, Pathology and Pharmacology. Curr. Drug Metab. 2015, 17, 4-29. [CrossRef] [PubMed]

4. Marin, J.J.G.; Briz, O.; Herraez, E.; Lozano, E.; Asensio, M.; Di Giacomo, S.; Romero, M.R.; Osorio-Padilla, L.M.; Santos-Llamas, A.I.; Serrano, M.A.; et al. Molecular bases of the poor response of liver cancer to chemotherapy. Clin. Res. Hepatol. Gastroenterol. 2018, 42, 182-192. [CrossRef]

5. Lozano, E.; Monte, M.J.; Briz, O.; Hernandez-Hernandez, A.; Banales, J.M.; Marin, J.J.; Macias, R.I. Enhanced antitumour drug delivery to cholangiocarcinoma through the apical sodium-dependent bile acid transporter (ASBT). J. Control Release 2015, 216, 93-102. [CrossRef]

6. Vavricka, S.R.; Jung, D.; Fried, M.; Grutzner, U.; Meier, P.J.; Kullak-Ublick, G.A. The human organic anion transporting polypeptide 8 (SLCO1B3) gene is transcriptionally repressed by hepatocyte nuclear factor 3beta in hepatocellular carcinoma. J. Hepatol. 2004, 40, 212-218. [CrossRef]

7. Martinez-Becerra, P.; Vaquero, J.; Romero, M.R.; Lozano, E.; Anadon, C.; Macias, R.I.; Serrano, M.A.; Grane-Boladeras, N.; Munoz-Bellvis, L.; Alvarez, L.; et al. No correlation between the expression of FXR and genes involved in multidrug resistance phenotype of primary liver tumors. Mol. Pharm. 2012, 9, 1693-1704. [CrossRef]

8. Pongmaneratanakul, S.; Tanasanvimon, S.; Pengsuparp, T.; Areepium, N. Prevalence of CTR1 and ERCC1 Polymorphisms and Response of Biliary Tract Cancer to Gemcitabine-Platinum Chemotherapy. Asian Pac. J. Cancer Prev. 2017, 18, 857-861.

9. Brandi, G.; Deserti, M.; Vasuri, F.; Farioli, A.; Degiovanni, A.; Palloni, A.; Frega, G.; Barbera, M.A.; De Lorenzo, S.; Garajova, I.; et al. Membrane Localization of Human Equilibrative Nucleoside Transporter 1 in Tumor Cells May Predict Response to Adjuvant Gemcitabine in Resected Cholangiocarcinoma Patients. Oncologist 2016, 21, 600-607. [CrossRef]

10. Kim, J.; Kim, H.; Lee, J.C.; Kim, J.W.; Paik, W.H.; Lee, S.H.; Hwang, J.H.; Ryu, J.K.; Kim, Y.T. Human equilibrative nucleoside transporter 1 (hENT1) expression as a predictive biomarker for gemcitabine chemotherapy in biliary tract cancer. PLoS ONE 2018, 13, e0209104. [CrossRef]

11. Grimm, D.; Lieb, J.; Weyer, V.; Vollmar, J.; Darstein, F.; Lautem, A.; Hoppe-Lotichius, M.; Koch, S.; Schad, A.; Schattenberg, J.M.; et al. Organic Cation Transporter 1 (OCT1) mRNA expression in hepatocellular carcinoma as a biomarker for sorafenib treatment. BMC Cancer 2016, 16, 94. [CrossRef] [PubMed]

12. Geier, A.; Macias, R.I.; Bettinger, D.; Weiss, J.; Bantel, H.; Jahn, D.; Al-Abdulla, R.; Marin, J.J. The lack of the organic cation transporter OCT1 at the plasma membrane of tumor cells precludes a positive response to sorafenib in patients with hepatocellular carcinoma. Oncotarget 2017, 8, 15846-15857. [CrossRef] [PubMed]

13. Lozano, E.; Macias, R.I.R.; Monte, M.J.; Asensio, M.; Del Carmen, S.; Sanchez-Vicente, L.; Alonso-Pena, M.; Al-Abdulla, R.; Munoz-Garrido, P.; Satriano, L.; et al. Causes of hOCT1-Dependent Cholangiocarcinoma Resistance to Sorafenib and Sensitization by Tumor-Selective Gene Therapy. Hepatology 2019, 70, 1246-1261. [CrossRef] [PubMed]

14. Visentin, M.; Van Rosmalen, B.V.; Hiller, C.; Bieze, M.; Hofstetter, L.; Verheij, J.; Kullak-Ublick, G.A.; Koepsell, H.; Phoa, S.S.; Tamai, I.; et al. Impact of Organic Cation Transporters (OCT-SLC22A) on Differential Diagnosis of Intrahepatic Lesions. Drug Metab. Dispos. 2017, 45, 166-173. [CrossRef]

15. Meier, R.; Bi, C.; Gaedigk, R.; Heruth, D.P.; Ye, S.Q.; Leeder, J.S.; Fridley, B.L. Ontogeny-related pharmacogene changes in the pediatric liver transcriptome. Pharm. Genom. 2018, 28, 86-94. [CrossRef]

16. Kubo, Y.; Aishima, S.; Tanaka, Y.; Shindo, K.; Mizuuchi, Y.; Abe, K.; Shirabe, K.; Maehara, Y.; Honda, H.; Oda, Y. Different expression of glucose transporters in the progression of intrahepatic cholangiocarcinoma. Hum. Pathol. 2014, 45, 1610-1617. [CrossRef]

17. Roh, M.S.; Jeong, J.S.; Kim, Y.H.; Kim, M.C.; Hong, S.H. Diagnostic utility of GLUT1 in the differential diagnosis of liver carcinomas. Hepatogastroenterology 2004, 51, 1315-1318.

18. Alves, V.A.; Pinheiro, C.; Morais-Santos, F.; Felipe-Silva, A.; Longatto-Filho, A.; Baltazar, F. Characterization of monocarboxylate transporter activity in hepatocellular carcinoma. World J. Gastroenterol. 2014, 20, 11780-11787. [CrossRef]

19. Wu, T.T.; Hsieh, Y.H.; Wu, C.C.; Tsai, J.H.; Hsieh, Y.S.; Huang, C.Y.; Liu, J.Y. Overexpression of anion exchanger 2 in human hepatocellular carcinoma. Chin. J. Physiol. 2006, 49, 192-198.

20. Hohenester, S.; Wenniger, L.M.; Paulusma, C.C.; Van Vliet, S.J.; Jefferson, D.M.; Elferink, R.P.; Beuers, U. A biliary HCO3- umbrella constitutes a protective mechanism against bile acid-induced injury in human cholangiocytes. Hepatology 2012, 55, 173-183. [CrossRef] 
21. Mazal, P.R.; Susani, M.; Wrba, F.; Haitel, A. Diagnostic significance of aquaporin-1 in liver tumors. Hum. Pathol. 2005, 36, 1226-1231. [CrossRef] [PubMed]

22. Sekine, S.; Shimada, Y.; Nagata, T.; Moriyama, M.; Omura, T.; Watanabe, T.; Hori, R.; Yoshioka, I.; Okumura, T.; Sawada, S.; et al. Prognostic significance of aquaporins in human biliary tract carcinoma. Oncol. Rep. 2012, 27, 1741-1747. [CrossRef] [PubMed]

23. Chen, X.; Sun, M.; Hu, Y.; Zhang, H.; Wang, Z.; Zhou, N.; Yan, X. FXYD6 is a new biomarker of cholangiocarcinoma. Oncol. Lett. 2014, 7, 393-398. [CrossRef] [PubMed]

24. Soini, Y.; Virkajarvi, N.; Raunio, H.; Paakko, P. Expression of P-glycoprotein in hepatocellular carcinoma: A potential marker of prognosis. J. Clin. Pathol. 1996, 49, 470-473. [CrossRef] [PubMed]

25. Srimunta, U.; Sawanyawisuth, K.; Kraiklang, R.; Pairojkul, C.; Puapairoj, A.; Titipungul, T.; Hahnvajanawong, C.; Tassaneeyakul, W.; Wongkham, C.; Wongkham, S.; et al. High expression of ABCC1 indicates poor prognosis in intrahepatic cholangiocarcinoma. Asian Pac. J. Cancer Prev. 2012, 13, 125-130.

26. Wang, B.L.; Zhai, H.Y.; Chen, B.Y.; Zhai, S.P.; Yang, H.Y.; Chen, X.P.; Zhao, W.T.; Meng, L. Clinical relationship between MDR1 gene and gallbladder cancer. Hepatobiliary Pancreat. Dis. Int. 2004, 3, 296-299. [PubMed]

27. Lagana, S.M.; Salomao, M.; Remotti, H.E.; Knisely, A.S.; Moreira, R.K. Bile salt export pump: A sensitive and specific immunohistochemical marker of hepatocellular carcinoma. Histopathology 2015, 66, 598-602. [CrossRef] [PubMed]

28. Fujikura, K.; Yamasaki, T.; Otani, K.; Kanzawa, M.; Fukumoto, T.; Ku, Y.; Hirose, T.; Itoh, T.; Zen, Y. BSEP and MDR3: Useful Immunohistochemical Markers to Discriminate Hepatocellular Carcinomas From Intrahepatic Cholangiocarcinomas and Hepatoid Carcinomas. Am. J. Surg. Pathol. 2016, 40, 689-696. [CrossRef] [PubMed]

29. Scheimann, A.O.; Strautnieks, S.S.; Knisely, A.S.; Byrne, J.A.; Thompson, R.J.; Finegold, M.J. Mutations in bile salt export pump (ABCB11) in two children with progressive familial intrahepatic cholestasis and cholangiocarcinoma. J. Pediatr. 2007, 150, 556-559. [CrossRef]

30. Tougeron, D.; Fotsing, G.; Barbu, V.; Beauchant, M. ABCB4/MDR3 gene mutations and cholangiocarcinomas. J. Hepatol. 2012, 57, 467-468. [CrossRef]

31. Cirqueira, C.S.; Felipe-Silva, A.S.; Wakamatsu, A.; Marins, L.V.; Rocha, E.C.; De Mello, E.S.; Alves, V.A.F. Immunohistochemical Assessment of the Expression of Biliary Transportation Proteins MRP2 and MRP3 in Hepatocellular Carcinoma and in Cholangiocarcinoma. Pathol. Oncol. Res. 2019, 25, 1363-1371. [CrossRef] [PubMed]

32. Tomonari, T.; Takeishi, S.; Taniguchi, T.; Tanaka, T.; Tanaka, H.; Fujimoto, S.; Kimura, T.; Okamoto, K.; Miyamoto, H.; Muguruma, N.; et al. MRP3 as a novel resistance factor for sorafenib in hepatocellular carcinoma. Oncotarget 2016, 7, 7207-7215. [CrossRef]

33. Larbcharoensub, N.; Sornmayura, P.; Sirachainan, E.; Wilasrusmee, C.; Wanmoung, H.; Janvilisri, T. Prognostic value of ABCG2 in moderately and poorly differentiated intrahepatic cholangiocarcinoma. Histopathology 2011, 59, 235-246. [CrossRef] [PubMed]

34. Pastor-Anglada, M.; Molina-Arcas, M.; Casado, F.J.; Bellosillo, B.; Colomer, D.; Gil, J. Nucleoside transporters in chronic lymphocytic leukaemia. Leukemia 2004, 18, 385-393. [CrossRef]

35. Sasaki, H.; Murakami, Y.; Uemura, K.; Sudo, T.; Hashimoto, Y.; Kondo, N.; Sueda, T. Concurrent analysis of human equilibrative nucleoside transporter 1 and ribonucleotide reductase subunit 1 expression increases predictive value for prognosis in cholangiocarcinoma patients treated with adjuvant gemcitabine-based chemotherapy. Br. J. Cancer 2014, 111, 1275-1284. [CrossRef] [PubMed]

36. Borbath, I.; Verbrugghe, L.; Lai, R.; Gigot, J.F.; Humblet, Y.; Piessevaux, H.; Sempoux, C. Human equilibrative nucleoside transporter 1 (hENT1) expression is a potential predictive tool for response to gemcitabine in patients with advanced cholangiocarcinoma. Eur. J. Cancer 2012, 48, 990-996. [CrossRef]

37. Criado, J.J.; Macias, R.I.; Medarde, M.; Monte, M.J.; Serrano, M.A.; Marin, J.J. Synthesis and characterization of the new cytostatic complex cis-diammineplatinum(II)-chlorocholylglycinate. Bioconjug. Chem. 1997, 8, 453-458. [CrossRef]

38. Criado, J.J.; Dominguez, M.F.; Medarde, M.; Fernandez, E.R.; Macias, R.I.; Marin, J.J. Structural characterization, kinetic studies, and in vitro biological activity of new cis-diamminebis-cholylglycinate $\left(\mathrm{O}, \mathrm{O}^{\prime}\right)$ $\mathrm{Pt}(\mathrm{II})$ and cis-diamminebis-ursodeoxycholate $\left(\mathrm{O}, \mathrm{O}^{\prime}\right) \mathrm{Pt}(\mathrm{II})$ complexes. Bioconjug. Chem. 2000, 11, 167-174. [CrossRef] 
39. Dominguez, M.F.; Macias, R.I.; Izco-Basurko, I.; De La Fuente, A.; Pascual, M.J.; Criado, J.M.; Monte, M.J.; Yajeya, J.; Marin, J.J. Low in vivo toxicity of a novel cisplatin-ursodeoxycholic derivative (Bamet-UD2) with enhanced cytostatic activity versus liver tumors. J. Pharmacol. Exp. Ther. 2001, 297, 1106-1112.

40. Kanai, Y.; Segawa, H.; Miyamoto, K.; Uchino, H.; Takeda, E.; Endou, H. Expression cloning and characterization of a transporter for large neutral amino acids activated by the heavy chain of 4F2 antigen (CD98). J. Biol. Chem. 1998, 273, 23629-23632. [CrossRef]

41. Janpipatkul, K.; Suksen, K.; Borwornpinyo, S.; Jearawiriyapaisarn, N.; Hongeng, S.; Piyachaturawat, P.; Chairoungdua, A. Downregulation of LAT1 expression suppresses cholangiocarcinoma cell invasion and migration. Cell Signal. 2014, 26, 1668-1679. [CrossRef] [PubMed]

42. Yothaisong, S.; Dokduang, H.; Anzai, N.; Hayashi, K.; Namwat, N.; Yongvanit, P.; Sangkhamanon, S.; Jutabha, P.; Endou, H.; Loilome, W. Inhibition of l-type amino acid transporter 1 activity as a new therapeutic target for cholangiocarcinoma treatment. Tumour Biol. 2017, 39, 1010428317694545. [CrossRef] [PubMed]

43. Brito, A.F.; Ribeiro, M.; Abrantes, A.M.; Mamede, A.C.; Laranjo, M.; Casalta-Lopes, J.E.; Goncalves, A.C.; Sarmento-Ribeiro, A.B.; Tralhao, J.G.; Botelho, M.F. New Approach for Treatment of Primary Liver Tumors: The Role of Quercetin. Nutr. Cancer 2016, 68, 250-266. [CrossRef] [PubMed]

44. Wang, C.; Lv, H.; Yang, W.; Li, T.; Fang, T.; Lv, G.; Han, Q.; Dong, L.; Jiang, T.; Jiang, B.; et al. SVCT-2 determines the sensitivity to ascorbate-induced cell death in cholangiocarcinoma cell lines and patient derived xenografts. Cancer Lett. 2017, 398, 1-11. [CrossRef]

45. Liu, B.; Herve, J.; Bioulac-Sage, P.; Valogne, Y.; Roux, J.; Yilmaz, F.; Boisgard, R.; Guettier, C.; Cales, P.; Tavitian, B.; et al. Sodium iodide symporter is expressed at the preneoplastic stages of liver carcinogenesis and in human cholangiocarcinoma. Gastroenterology 2007, 132, 1495-1503. [CrossRef]

46. Herraez, E.; Lozano, E.; Macias, R.I.; Vaquero, J.; Bujanda, L.; Banales, J.M.; Marin, J.J.; Briz, O. Expression of SLC22A1 variants may affect the response of hepatocellular carcinoma and cholangiocarcinoma to sorafenib. Hepatology 2013, 58, 1065-1073. [CrossRef]

47. Al-Abdulla, R.; Lozano, E.; Macias, R.I.R.; Monte, M.J.; Briz, O.; O’Rourke, C.J.; Serrano, M.A.; Banales, J.M.; Avila, M.A.; Martinez-Chantar, M.L.; et al. Epigenetic events involved in organic cation transporter 1-dependent impaired response of hepatocellular carcinoma to sorafenib. Br. J. Pharmacol. 2019, 176, 787-800. [CrossRef]

48. Urtasun, N.; Boces-Pascual, C.; Boix, L.; Bruix, J.; Pastor-Anglada, M.; Perez-Torras, S. Role of drug-dependent transporter modulation on the chemosensitivity of cholangiocarcinoma. Oncotarget 2017, 8, 90185-90196. [CrossRef]

49. Lagas, J.S.; Van Waterschoot, R.A.; Sparidans, R.W.; Wagenaar, E.; Beijnen, J.H.; Schinkel, A.H. Breast cancer resistance protein and P-glycoprotein limit sorafenib brain accumulation. Mol. Cancer Ther. 2010, 9, 319-326. [CrossRef]

50. Tepsiri, N.; Chaturat, L.; Sripa, B.; Namwat, W.; Wongkham, S.; Bhudhisawasdi, V.; Tassaneeyakul, W. Drug sensitivity and drug resistance profiles of human intrahepatic cholangiocarcinoma cell lines. World J. Gastroenterol. 2005, 11, 2748-2753. [CrossRef]

51. Polgar, O.; Bates, S.E. ABC transporters in the balance: Is there a role in multidrug resistance? Biochem. Soc. Trans. 2005, 33, 241-245. [CrossRef] [PubMed]

52. Kathawala, R.J.; Gupta, P.; Ashby, C.R., Jr.; Chen, Z.S. The modulation of ABC transporter-mediated multidrug resistance in cancer: A review of the past decade. Drug Resist. Updat. 2015, 18, 1-17. [CrossRef] [PubMed]

53. Bates, S.; Kang, M.; Meadows, B.; Bakke, S.; Choyke, P.; Merino, M.; Goldspiel, B.; Chico, I.; Smith, T.; Chen, C.; et al. A Phase I study of infusional vinblastine in combination with the P-glycoprotein antagonist PSC 833 (valspodar). Cancer 2001, 92, 1577-1590. [CrossRef]

54. Cripe, L.D.; Uno, H.; Paietta, E.M.; Litzow, M.R.; Ketterling, R.P.; Bennett, J.M.; Rowe, J.M.; Lazarus, H.M.; Luger, S.; Tallman, M.S. Zosuquidar, a novel modulator of P-glycoprotein, does not improve the outcome of older patients with newly diagnosed acute myeloid leukemia: A randomized, placebo-controlled trial of the Eastern Cooperative Oncology Group 3999. Blood 2010, 116, 4077-4085. [CrossRef]

55. Marienfeld, C.; Tadlock, L.; Yamagiwa, Y.; Patel, T. Inhibition of cholangiocarcinoma growth by tannic acid. Hepatology 2003, 37, 1097-1104. [CrossRef]

56. Naus, P.J.; Henson, R.; Bleeker, G.; Wehbe, H.; Meng, F.; Patel, T. Tannic acid synergizes the cytotoxicity of chemotherapeutic drugs in human cholangiocarcinoma by modulating drug efflux pathways. J. Hepatol. 2007, 46, 222-229. [CrossRef] 
57. Huang, G.L.; Shen, D.Y.; Cai, C.F.; Zhang, Q.Y.; Ren, H.Y.; Chen, Q.X. beta-escin reverses multidrug resistance through inhibition of the GSK3beta/beta-catenin pathway in cholangiocarcinoma. World J. Gastroenterol. 2015, 21, 1148-1157. [CrossRef]

58. Hahnvajanawong, C.; Wattanawongdon, W.; Chomvarin, C.; Anantachoke, N.; Kanthawong, S.; Sripa, B.; Reutrakul, V. Synergistic effects of isomorellin and forbesione with doxorubicin on apoptosis induction in human cholangiocarcinoma cell lines. Cancer Cell Int. 2014, 14, 68. [CrossRef]

59. Ling, S.; Feng, T.; Ke, Q.; Fan, N.; Li, L.; Li, Z.; Dong, C.; Wang, C.; Xu, F.; Li, Y.; et al. Metformin inhibits proliferation and enhances chemosensitivity of intrahepatic cholangiocarcinoma cell lines. Oncol. Rep. 2014, 31, 2611-2618. [CrossRef]

60. Seeree, P.; Janvilisri, T.; Kangsamaksin, T.; Tohtong, R.; Kumkate, S. Downregulation of ABCA1 and ABCG1 transporters by simvastatin in cholangiocarcinoma cells. Oncol. Lett. 2019, 18, 5173-5184. [CrossRef]

61. Liu, Z.H.; Ma, Y.L.; He, Y.P.; Zhang, P.; Zhou, Y.K.; Qin, H. Tamoxifen reverses the multi-drug-resistance of an established human cholangiocarcinoma cell line in combined chemotherapeutics. Mol. Biol. Rep. 2011, 38, 1769-1775. [CrossRef] [PubMed]

62. Dai, C.L.; Tiwari, A.K.; Wu, C.P.; Su, X.D.; Wang, S.R.; Liu, D.G.; Ashby, C.R., Jr.; Huang, Y.; Robey, R.W.; Liang, Y.J.; et al. Lapatinib (Tykerb, GW572016) reverses multidrug resistance in cancer cells by inhibiting the activity of ATP-binding cassette subfamily B member 1 and G member 2. Cancer Res. 2008, 68, 7905-7914. [CrossRef] [PubMed]

63. Tiwari, A.K.; Sodani, K.; Wang, S.R.; Kuang, Y.H.; Ashby, C.R., Jr.; Chen, X.; Chen, Z.S. Nilotinib (AMN107, Tasigna) reverses multidrug resistance by inhibiting the activity of the ABCB1/Pgp and ABCG2/BCRP/MXR transporters. Biochem. Pharmacol. 2009, 78, 153-161. [CrossRef] [PubMed]

64. Shi, Z.; Peng, X.X.; Kim, I.W.; Shukla, S.; Si, Q.S.; Robey, R.W.; Bates, S.E.; Shen, T.; Ashby, C.R., Jr.; Fu, L.W.; et al. Erlotinib (Tarceva, OSI-774) antagonizes ATP-binding cassette subfamily B member 1 and ATP-binding cassette subfamily G member 2-mediated drug resistance. Cancer Res. 2007, 67, 11012-11102. [CrossRef] [PubMed]

65. Sims, J.T.; Ganguly, S.S.; Bennett, H.; Friend, J.W.; Tepe, J.; Plattner, R. Imatinib reverses doxorubicin resistance by affecting activation of STAT3-dependent NF-kappaB and HSP27/p38/AKT pathways and by inhibiting ABCB1. PLoS ONE 2013, 8, e55509. [CrossRef]

66. Seubwai, W.; Vaeteewoottacharn, K.; Kraiklang, R.; Umezawa, K.; Okada, S.; Wongkham, S. Inhibition of NF-kappaB Activity Enhances Sensitivity to Anticancer Drugs in Cholangiocarcinoma Cells. Oncol. Res. 2016, 23, 21-28. [CrossRef]

67. Wang, C.; Ye, H.; Zhang, L.; Cheng, Y.; Xu, S.; Zhang, P.; Zhang, Z.; Bai, J.; Meng, F.; Zhong, L.; et al. Enhanced expression of ten-eleven translocation 1 reverses gemcitabine resistance in cholangiocarcinoma accompanied by a reduction in P-glycoprotein expression. Cancer Med. 2019, 8, 990-1003. [CrossRef]

68. Li, Q.; Xia, X.; Ji, J.; Ma, J.; Tao, L.; Mo, L.; Chen, W. MiR-199a-3p enhances cisplatin sensitivity of cholangiocarcinoma cells by inhibiting mTOR signaling pathway and expression of MDR1. Oncotarget 2017, 8, 33621-33630. [CrossRef]

69. Shen, D.Y.; Zhang, W.; Zeng, X.; Liu, C.Q. Inhibition of Wnt/beta-catenin signaling downregulates P-glycoprotein and reverses multi-drug resistance of cholangiocarcinoma. Cancer Sci. 2013, 104, 1303-1308. [CrossRef]

(C) 2020 by the authors. Licensee MDPI, Basel, Switzerland. This article is an open access article distributed under the terms and conditions of the Creative Commons Attribution (CC BY) license (http://creativecommons.org/licenses/by/4.0/). 